\title{
A structured growth model for Cynara cardunculus cell suspension
}

\author{
P. M. N. A. C. Pires Cabral, M. E. Lima Costa, J. M. S. Cabral
}

\begin{abstract}
In this study a model was developed to describe the growth of Cynara cardunculus L. suspended cells as a function of the availability of two substrates, sucrose as the carbon and energy source and phosphate. It was assumed that the maintenance energy need was fulfilled by the consumption of extracellular carbohydrates, in nonlimiting conditions, or by the consumption of structural biomass when sucrose is depleted. A production of secondary metabolites was also assumed. This model was developed based on a structured model previously described by Van Gulik et al. (1993). The model was applied to the experimental results of $C$. cardunculus suspended cells grown in a Gamborg $B_{5}$ medium supplemented with $2 \%$ sucrose, using a non-linear regression program.

\section{List of symbols}

$C_{\mathrm{C}} \quad$ C-pool concentration, $\mathrm{mg} \cdot \mathrm{ml}^{-1}$

$C_{\mathrm{F}} \quad$ F-pool concentration, $\mathrm{mg} \cdot \mathrm{ml}^{-1}$

$C_{\mathrm{F}, \mathrm{ext}} \quad$ Extracellular phosphate concentration, $\mathrm{mg} \cdot \mathrm{ml}^{-1}$

$C_{\mathrm{K}} \quad \mathrm{K}$-pool concentration, $\mathrm{mg} \cdot \mathrm{ml}^{-1}$

$C_{\mathrm{P}} \quad$ Secondary metabolites concentration, $\mathrm{mg} \cdot \mathrm{ml}^{-1}$

$C_{\mathrm{S}} \quad$ Extracellular sucrose concentration, $\mathrm{mg} \cdot \mathrm{ml}^{-1}$

$C_{\mathrm{X}} \quad$ Biomass concentration, $\mathrm{mg} \cdot \mathrm{ml}^{-1}$

$K \quad$ Formation rate constant of secondary metabolites, day ${ }^{-1}$

$k_{\mathrm{F}} \quad$ Intracellular phosphate saturation constant, $\mathrm{mg} \cdot \mathrm{mg}^{-1}$

$k_{\mathrm{F} \text {,ext }} \quad$ Extracellular phosphate saturation constant, $\mathrm{mg} \cdot \mathrm{ml}^{-1}$

$k_{\mathrm{m}} \quad$ Conversion factor, $\mathrm{mg} \cdot \mathrm{ml}^{-1}$

$k_{\mathrm{S}} \quad$ Extracellular sucrose saturation constant, $\mathrm{mg} \cdot \mathrm{ml}^{-1}$

$m_{\mathrm{S}} \quad$ Maintenance coefficient, $\mathrm{mg} \cdot \mathrm{mg}^{-1} \cdot \mathrm{h}^{-1}$
\end{abstract}

Received: 6 September 1999

P. M. N. A. C. Pires Cabral ( $\square)$

Escola Superior de Tecnologia, Universidade do Algarve, Campus da Penha, 8000 Faro, Portugal

M. E. Lima Costa

Unidade de Ciências e Tecnologias Agrárias, Universidade do Algarve, Campus de Gambelas, 8000 Faro, Portugal

J. M. S. Cabral

Laboratório de Engenharia Bioquímica,

Centro de Engenharia Biológica e Química,

Instituto Superior Técnico, 1000 Lisboa, Portugal
$q_{\mathrm{F}, \max }$ $q_{\mathrm{P}}$

$q_{\mathrm{sC}, \mathrm{max}}$

$q_{\mathrm{SK}, \max }$

$r_{\mathrm{CP}}$

$r_{\mathrm{F}, \mathrm{ext}}, r_{\mathrm{F}}$

$r_{\mathrm{Cm}}$

$r_{\mathrm{MS}}$

$r_{\mathrm{SC}}$

$r_{\mathrm{SC}}$

$r_{\mathrm{SK}}$

$r_{\mathrm{Sm}}$

$Y_{\mathrm{CP}}$

$Y_{\text {SC }}$

$Y_{\mathrm{SK}}$

$Y_{\mathrm{SX}}$

$Z_{\mathrm{C}}$

$Z_{\mathrm{F}}$

$Z_{\mathrm{K}}$

$\mu_{\max }$
Maximum specific rate of F-pool formation, $\mathrm{mg} \cdot \mathrm{mg}^{-1} \cdot$ day $^{-1}$

Specific formation rate of secondary metabolites, $\mathrm{mg} \cdot \mathrm{g}^{-1} \cdot$ day $^{-1}$

Maximum specific rate of C-pool formation, $\mathrm{mg} \cdot \mathrm{mg}^{-1} \cdot$ day $^{-1}$

Maximum specific rate of K-pool formation, $\mathrm{mg} \cdot \mathrm{mg}^{-1} \cdot$ day $^{-1}$

Secondary metabolites formation rate, $\mathrm{mg} \cdot \mathrm{ml}^{-1} \cdot$ day $^{-1}$

Rate of phosphate uptake and F-pool formation, $\mathrm{mg} \cdot \mathrm{ml}^{-1} \cdot$ day $^{-1}$

Rate consumption of C-pool for maintenance, $\mathrm{mg} \cdot \mathrm{ml}^{-1} \cdot$ day $^{-1}$

Total rate of carbohydrates consumption for maintenance, $\mathrm{mg} \cdot \mathrm{ml}^{-1} \cdot \mathrm{day}^{-1}$

Rate of sucrose conversion in C-pool, $\mathrm{mg} \cdot \mathrm{ml}^{-1} \cdot$ day $^{-1}$

Rate of sucrose conversion in K-pool, $\mathrm{mg} \cdot \mathrm{ml}^{-1} \cdot$ day $^{-1}$

Rate consumption of sucrose for maintenance, $\mathrm{mg} \cdot \mathrm{ml}^{-1} \cdot$ day $^{-1}$

Yield coefficient conversion of C-pool

in secondary metabolites, $\mathrm{mg} \cdot \mathrm{mg}^{-1}$

Yield coefficient conversion of sucrose in C-pool, $\mathrm{mg} \cdot \mathrm{mg}^{-1}$

Yield coefficient conversion of sucrose in $\mathrm{K}$-pool, $\mathrm{mg} \cdot \mathrm{mg}^{-1}$

Yield coefficient conversion of sucrose in biomass, $\mathrm{mg} \cdot \mathrm{mg}^{-1}$

Fraction of structural biomass (C-pool)

Fraction of intracellular phosphate (F-pool)

Fraction of high energetic compounds (K-pool)

Maximum specific growth rate, day ${ }^{-1}$
1

\section{Introduction}

Plant cell suspension cultures of Cynara cardunculus L. has been previously studied by Lima Costa who optimized the growth parameters in batch system, and presented a kinetic growth study of $C$. cardunculus suspended cells in biological reactors $[1,2]$. This author studied the applicability of some unstructured kinetic models to C. cardunculus cells growth, such as the Monod, the Herbert, the Pirt and the Beeftink et al. models [3] and how the kinetics of these plant cells were affected by extracellular sucrose and phosphate concentrations (not published). Lima Costa [2] suggested the development of a structured model of growth and product synthesis which would describe more 


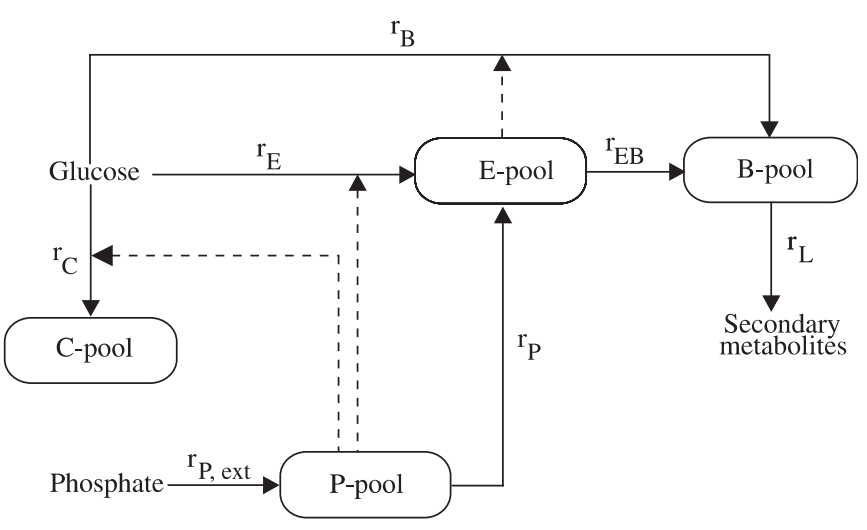

Fig. 1. Growth model of Catharanthus roseus (and Nicotiana tabacum) suspended cells (adapted from Van Gulik et al. [4])

accurately plant tissue cultivation phenomena, since it accounts for the multiplicity of cell components and their interactions.

Van Gulik et al. [4] developed a structured model for the description of growth kinetics of Nicotiana tabacum and Catharanthus roseus suspended cells. According to these authors the cell's growth was a function of the availability of glucose and phosphate growth limiting substrates. Under non-limiting conditions these two substrates were accumulated by C. roseus (and by N. tabacum) cells. It was assumed that glucose and phosphate were subsequently converted into low molecular weight phosphorylated compounds, which served as energy carriers and/or precursors to synthesize macromolecules. Therefore the rate of biomass formation was assumed to depend on the intracellular level of these compounds. It was further included in the model a degradation process of part of the biomass to form extracellular lysis products (Fig. 1). Based on the above, the authors [4] divided the biomass into four different pools of compounds: (i) Free intracellular phosphate (P-pool); (ii) Low molecular weight phosphorylated compounds (E-pool); (iii) Storage carbohydrates (C-pool); and (iv) Structural biomass (B-pool).

Based on Lima Costa previous work [2] and Van Gulik et al. [4] model, a structured model for the description of growth of Cynara cardunculus cells was developed and is described in this article.

\section{2}

\section{Biological model concept}

In the present work the growth of Cynara cardunculus L. suspended cells was modeled [5] as a function of the availability of two substrates, sucrose as the carbon and energy source and phosphate. All other essential nutrients for cell growth were assumed to be present in non-limiting amounts.

Sucrose was supposed to be hydrolyzed outside the cell, with production of glucose and fructose that are transported into the cell (carrier-mediated transport) and partially metabolized by catabolic processes, with production of high energetic compounds such as ATP, ADP, AMP, CTP, GTP, UTP, NADP and NADPH, and partially converted by anabolic pathways on structural biomass. It was further assumed that no storage of carbohydrates occurs [2].

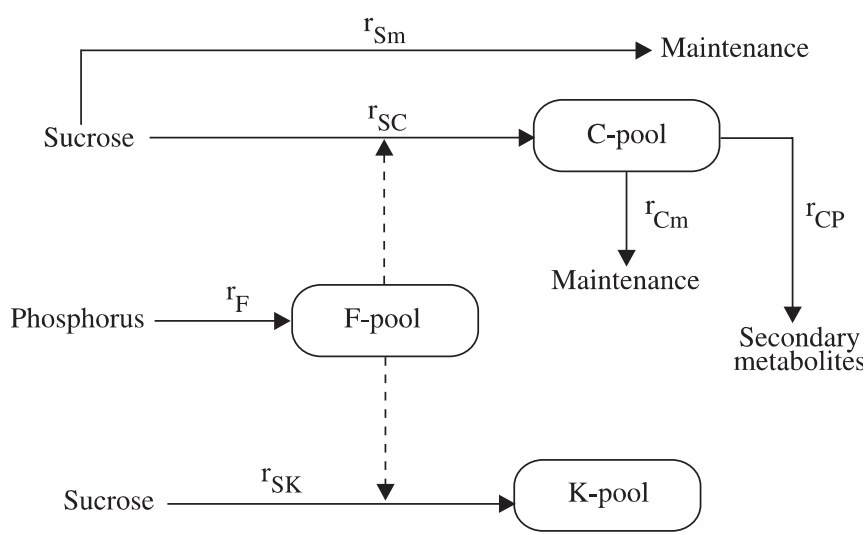

Fig. 2. Growth model of Cynara cardunculus L. suspended cells

Table 1. Model characteristics

\begin{tabular}{lll}
\hline Process & Rate & $\begin{array}{l}\text { Yield } \\
\text { coefficient }\end{array}$ \\
\hline $\begin{array}{l}\text { Conversion of } \\
\text { sucrose in C-pool }\end{array}$ & $r_{\mathrm{SC}}$ & $Y_{\mathrm{SC}}$ \\
$\begin{array}{l}\text { Conversion of } \\
\text { sucrose in K-pool }\end{array}$ & $r_{\mathrm{SK}}$ & $Y_{\mathrm{SK}}$ \\
$\begin{array}{l}\text { Consumption of sucrose for } \\
\text { maintenance energy needs }\end{array}$ & $r_{\mathrm{Sm}}$ & - \\
$\begin{array}{l}\text { Consumption of C-pool for } \\
\text { maintenance energy needs }\end{array}$ & $r_{\mathrm{Cm}}$ & - \\
$\begin{array}{l}\text { Uptake of extracellular } \\
\text { phosphate }\end{array}$ & $r_{\mathrm{F}}$ & - \\
$\begin{array}{l}\text { Secondary metabolites } \\
\text { formation and its transport } \\
\text { to the extracellular medium }\end{array}$ & $r_{\mathrm{CP}}$ & $Y_{\mathrm{CP}}$ \\
\hline
\end{tabular}

Inorganic extracellular phosphate was considered to be carrier-mediated transported into the cell, partially converted together with glucose and fructose into low molecular weight phosphorylated compounds and the excess was stored in the vacuoles [2].

Maintenance energy needs were assumed to be fulfilled by the consumption of extracellular carbohydrates, in nonlimiting conditions, or by consumption of structural biomass when sucrose was depleted. It was also assumed that secondary metabolites were produced and transported to the extracellular medium by a diffusion mechanism.

The biomass was therefore divided into three pools of compounds as shown in Fig. 2: (i) Structural biomass (C-pool); (ii) High energetic compounds (K-pool); and (iii) Storage of inorganic phosphate and low molecular weight phosphorylated compounds (F-pool).

Table 1 explicits the yield coefficients and the rates of conversion processes represented in the model diagram of Fig. 2.

\section{Mathematical model definition}

\section{1}

\section{Balance equations}

A distinction is made between biotic compounds (i.e. compounds which are part of the biomass) and abiotic compounds (i.e. compounds outside the cells). 
The general state vector $\mathbf{C}$ of all compounds inside a culture system with growing cells, can thus be divided into a state vector $\mathbf{X}$ of biotic compounds and a state vector $\mathbf{Y}$ of abiotic compounds:

$\mathbf{C}=[\mathbf{X}, \mathbf{Y}]$.

In this model the biotic phase consists of two compounds, namely the two biomass pools and is defined as:

$\mathbf{X}=\left[C_{\mathrm{C}}, C_{\mathrm{K}}, C_{\mathrm{F}}\right]$,

and the abiotic phase consists of the three compounds sucrose $(\mathrm{S})$, extracellular phosphate $(\mathrm{F}$, ext) and secondary metabolites $(\mathrm{P})$ and is defined as:

$\mathbf{Y}=\left[C_{\mathrm{S}}, C_{\mathrm{F}, \mathrm{ext}}\right]$.

The balance equation for the abiotic compounds, in a constant volume system, in a batch culture is:

$\frac{\mathrm{d} C_{\mathrm{S}}}{\mathrm{d} t}=-r_{\mathrm{S}}$,

with

$r_{\mathrm{S}}=r_{\mathrm{SC}}+r_{\mathrm{SK}}+r_{\mathrm{Sm}}$

and

$\frac{\mathrm{d} C_{\mathrm{F}, \mathrm{ext}}}{\mathrm{d} t}=-r_{\mathrm{F}, \mathrm{ext}}$,

$\frac{\mathrm{d} C_{\mathrm{P}}}{\mathrm{d} t}=r_{\mathrm{CP}}$.

The biotic compounds have to be expressed as fractions of the total biomass, since they leave and enter the culture system only as constituents of the cells:

$\mathbf{Z}=\left[\frac{C_{\mathrm{C}}}{C_{\mathrm{X}}}, \frac{C_{\mathrm{K}}}{C_{\mathrm{X}}}, \frac{C_{\mathrm{F}}}{C_{\mathrm{X}}}\right]$,

or

$\mathbf{Z}=\left[Z_{\mathrm{C}}, Z_{\mathrm{K}}, Z_{\mathrm{F}}\right]$,

therefore the net formation rates of the three biotic compounds are:

$\frac{\mathrm{d} Z_{\mathrm{C}}}{\mathrm{d} t}=\frac{1}{C_{\mathrm{X}}}\left[Y_{\mathrm{SC}} r_{\mathrm{SC}}-\frac{r_{\mathrm{CP}}}{Y_{\mathrm{CP}}}-Y_{\mathrm{SC}} r_{\mathrm{Cm}}-\left(\frac{\mathrm{d} C_{\mathrm{X}}}{\mathrm{d} t}\right) Z_{\mathrm{C}}\right]$,

$\frac{\mathrm{d} Z_{\mathrm{K}}}{\mathrm{d} t}=\frac{1}{C_{\mathrm{X}}}\left[Y_{\mathrm{SK}} r_{\mathrm{SK}}-\left(\frac{\mathrm{d} C_{\mathrm{X}}}{\mathrm{d} t}\right) Z_{\mathrm{K}}\right]$,

$\frac{\mathrm{d} Z_{\mathrm{F}}}{\mathrm{d} t}=\frac{1}{C_{\mathrm{X}}}\left[r_{\mathrm{F}}-\left(\frac{\mathrm{d} C_{\mathrm{X}}}{\mathrm{d} t}\right) Z_{\mathrm{F}}\right]$.

\section{2}

\section{Constitutive equations}

\subsection{1}

\section{Conversion of sucrose in C-pool}

The rate of sucrose uptake from the growth medium and conversion in C-pool, $r_{\mathrm{SC}}$, was assumed to be proportional to the fraction of structural biomass, $Z_{\mathrm{C}}$, to depend on the intracellular phosphate level, $Z_{\mathrm{F}}$, and on the extracellular sucrose concentration, $C_{\mathrm{S}}$, according to:
$r_{\mathrm{SC}}=q_{\mathrm{SC}, \max } Z_{\mathrm{C}} C_{\mathrm{X}} \frac{Z_{\mathrm{F}}}{k_{\mathrm{F}}+Z_{\mathrm{F}}} \frac{C_{\mathrm{S}}}{k_{\mathrm{S}}+C_{\mathrm{S}}}$

\subsection{2}

\section{Conversion of sucrose in K-pool}

The rate of sucrose uptake from the growth medium and conversion in K-pool, $r_{\mathrm{SK}}$, was assumed to be proportional to the fraction of energy pool (K-pool), $Z_{\mathrm{K}}$, to depend on the intracellular phosphate level, $Z_{\mathrm{F}}$, and on the extracellular sucrose concentration, $C_{S}$, according to:

$r_{\mathrm{SK}}=q_{\mathrm{SK}, \max } Z_{\mathrm{K}} C_{\mathrm{X}} \frac{Z_{\mathrm{F}}}{k_{\mathrm{F}}+Z_{\mathrm{F}}} \frac{C_{\mathrm{S}}}{k_{\mathrm{S}}+C_{\mathrm{S}}}$.

\subsection{3}

\section{Maintenance energy needs}

The total rate of carbohydrate consumption for maintenance of the cells, $r_{\mathrm{MS}}$, was assumed to be proportional to the amount of structural biomass:

$r_{\mathrm{MS}}=m_{\mathrm{S}} Z_{\mathrm{C}} C_{\mathrm{X}}$.

When the level of sucrose in the extracellular medium is high, it was consumed to supply the cell's metabolic requirements with a rate, $r_{\mathrm{Sm}}$ :

$r_{\mathrm{Sm}}=r_{\mathrm{MS}} \frac{C_{\mathrm{S}}}{C_{\mathrm{S}}+k_{\mathrm{m}} Z_{\mathrm{C}}}$.

When sucrose is depleted, biomass was consumed, with a rate, $r_{\mathrm{Cm}}$, to fulfill the maintenance energy needs:

$r_{\mathrm{Cm}}=r_{\mathrm{MS}} \frac{k_{\mathrm{m}} Z_{\mathrm{C}}}{C_{\mathrm{S}}+k_{\mathrm{m}} Z_{\mathrm{C}}}$.

\subsection{4}

\section{Uptake of extracellular phosphate}

The rate of phosphate uptake from the growth medium, $r_{\mathrm{F}}$, was assumed to depend on the extracellular phosphate concentration, $C_{\mathrm{F} \text {,ext }}$, according to:

$r_{\mathrm{F}}=q_{\mathrm{F}, \text { max }} C_{\mathrm{X}} \frac{C_{\mathrm{F}, \mathrm{ext}}}{k_{\mathrm{F}, \mathrm{ext}}+C_{\mathrm{F}, \mathrm{ext}}}$.

\subsection{5}

\section{Secondary products formation}

The rate of production of secondary metabolites, $r_{\mathrm{CP}}$, was supposed to be a linear function of structural biomass fraction, $Z_{\mathrm{C}}$ :

$r_{\mathrm{CP}}=q_{\mathrm{P}} Z_{\mathrm{C}} C_{\mathrm{X}}$.

\section{3}

\section{Maximum specific growth rate}

It is assumed a steady state growth for the derivation of the maximum specific growth rate. Under these conditions, the left hand side of the balance Eqs. (10)-(12) becomes zero. After rearrangement of the Eq. (10) the maximum 
rate of biomass formation under steady state conditions can be expressed as:

$\frac{\mathrm{d} C_{\mathrm{X}}}{\mathrm{d} t}=\mu_{\max } C_{\mathrm{X}}=\frac{Y_{\mathrm{SC}} r_{\mathrm{SC}}-\frac{r_{\mathrm{CP}}}{Y_{\mathrm{CP}}}-Y_{\mathrm{SC}} r_{\mathrm{Cm}}}{Z_{\mathrm{C}}}$.

At high extracellular sucrose and phosphate concentrations the Monod terms of the Eq. (13) and Eq. (18) equals unity. Besides if extracellular sucrose concentration was higher than the fraction of structural biomass $\left(C_{\mathrm{S}} \gg k_{\mathrm{m}} Z_{\mathrm{C}}\right)$ the Monod term of Eq. (17) equals zero. After incorporation of Eqs. (13), (17) and (18) into Eq. (20) it yields the Eq. (21):

$$
\begin{aligned}
& k_{\mathrm{F}} \mu_{\mathrm{max}}^{2}+\mu_{\max }\left(q_{\mathrm{F}, \max }+\frac{q_{\mathrm{P}}}{Y_{\mathrm{CP}}} k_{\mathrm{F}}\right) \\
& \quad+q_{\mathrm{F}, \max }\left(\frac{q_{\mathrm{P}}}{Y_{\mathrm{CP}}}-Y_{\mathrm{SC}} q_{\mathrm{SC}, \max }\right)=0 .
\end{aligned}
$$

The positive solution of this equation gives the maximum specific growth rate:

$$
\begin{aligned}
\mu_{\max }= & -\frac{1}{2}\left(\frac{q_{\mathrm{F}, \max }}{k_{\mathrm{F}}}+\frac{q_{\mathrm{P}}}{Y_{\mathrm{CP}}}\right)+\frac{1}{2}\left[\left(\frac{q_{\mathrm{F}, \max }}{k_{\mathrm{F}}}+\frac{q_{\mathrm{P}}}{Y_{\mathrm{CP}}}\right)^{2}\right. \\
& \left.+4 \frac{q_{\mathrm{F}, \max }}{k_{\mathrm{F}}}\left(Y_{\mathrm{SC}} q_{\mathrm{SC}, \max }-\frac{q_{\mathrm{P}}}{Y_{\mathrm{CP}}}\right)\right]^{\frac{1}{2}} .
\end{aligned}
$$

\section{4}

\section{Parameters estimation}

In order to obtain useful predictions from the mathematical model, the next parameter values are estimated: (i) Yield coefficients $Y_{\mathrm{SC}}, Y_{\mathrm{SK}}$ and $Y_{\mathrm{CP}}$; (ii) Specific conversion rates $q_{\mathrm{SC}, \max }, q_{\mathrm{SK}, \max }, q_{\mathrm{P}}$ and $q_{\mathrm{F}, \max }$; (iii) Maintenance coefficient, $m_{\mathrm{S}}$; (iv) Saturation constants, $k_{\mathrm{F} \text {,ext }}, k_{\mathrm{F}}$ and $k_{\mathrm{S}} ;(\mathrm{v})$ Conversion factor, $k_{\mathrm{m}}$.

The yield coefficient of conversion of C-pool in secondary metabolites, $Y_{\mathrm{CP}}$, the specific phenol formation rate, $q_{\mathrm{P}}$, the maintenance coefficient, $m_{\mathrm{S}}$, and the yield coefficient of conversion of sucrose into biomass, $Y_{\mathrm{SX}}$, for Cynara cardunculus suspended cells growth in $\mathrm{B}_{5}$ medium supplemented with $2 \%$ sucrose, were previously obtained [2].

It is considered that $Y_{\mathrm{SX}}=0.58 \pm 0.02(\mathrm{mg}$ dry weight $) \cdot(\mathrm{mg} \text { sucrose })^{-1}$ corresponds to the total conversion of sucrose in biomass. Assuming that $1 \%$ of biomass is represented by $\mathrm{K}$-pool and $99 \%$ is structural biomass as C-pool, the yield coefficients of conversion of sucrose in $\mathrm{K}$-pool and C-pool are:

$Y_{\mathrm{SK}}=0.0058 \pm 0.0002(\mathrm{mg}$ dry weight $) \cdot(\mathrm{mg} \mathrm{sucrose})^{-1}$, $Y_{\mathrm{SC}}=0.5742 \pm 0.0198(\mathrm{mg}$ dry weight $) \cdot(\mathrm{mg} \mathrm{sucrose})^{-1}$. The saturation constants and the conversion factor, $k_{\mathrm{m}}$, is calculated by a non-linear regression using ROK [6]. This computer program solves the differential equations system which define the model, using a combination of a fourth-order Runge-Kutta procedure and an algorithm based on a Powell's conjugate directions method.

The differential equations system obtained from the balance and constitutive equations above are defined as:

$$
\begin{aligned}
& \frac{\mathrm{d} C_{\mathrm{S}}}{\mathrm{d} t}=-\left(q_{\mathrm{SC}, \text { max }} C_{\mathrm{C}} \frac{C_{\mathrm{F}}}{k_{\mathrm{F}} C_{\mathrm{X}}+C_{\mathrm{F}}} \frac{C_{\mathrm{S}}}{k_{\mathrm{S}}+C_{\mathrm{S}}}\right) \\
&-\left(q_{\mathrm{SK}, \text { max }} C_{\mathrm{K}} \frac{C_{\mathrm{F}}}{k_{\mathrm{F}} C_{\mathrm{X}}+C_{\mathrm{F}}} \frac{C_{\mathrm{S}}}{k_{\mathrm{S}}+C_{\mathrm{S}}}\right) \\
&-\left(m_{\mathrm{S}} C_{\mathrm{C}} \frac{C_{\mathrm{S}}}{C_{\mathrm{S}}+\left(\left(k_{\mathrm{m}} C_{\mathrm{C}}\right) / C_{\mathrm{X}}\right)}\right) \\
& \frac{\mathrm{d} C_{\mathrm{F}, \text { ext }}}{\mathrm{d} t}=-q_{\mathrm{F}, \max } C_{\mathrm{X}} \frac{C_{\mathrm{F}, \text { ext }}}{k_{\mathrm{F}, \text { ext }}+C_{\mathrm{F}, \text { ext }}}, \\
& \frac{\mathrm{d} C_{\mathrm{X}}}{\mathrm{d} t}=\left(Y_{\mathrm{SC}} q_{\mathrm{SC}} C_{\mathrm{X}} \frac{C_{\mathrm{F}}}{k_{\mathrm{F}} C_{\mathrm{X}}+C_{\mathrm{F}}} \frac{C_{\mathrm{S}}}{k_{\mathrm{S}}+C_{\mathrm{S}}}\right)-\left(\frac{q_{\mathrm{P}}}{Y_{\mathrm{CP}}} C_{\mathrm{X}}\right) \\
&-\left(Y_{\mathrm{SC}} m_{\mathrm{S}} C_{\mathrm{X}} \frac{k_{\mathrm{m}} C_{\mathrm{C}}}{C_{\mathrm{S}} C_{\mathrm{X}}+k_{\mathrm{m}} C_{\mathrm{C}}}\right), \\
& \frac{\mathrm{d} C_{\mathrm{P}}}{\mathrm{d} t}= q_{\mathrm{P}} C_{\mathrm{C}} .
\end{aligned}
$$

5

\section{Results and discussion}

A structured model describing the growth and metabolite production of Cynara cardunculus L. suspended cells has been developed together with those assumptions upon which it is based.

All conversion processes can be described by six reactions of which the rates $\left(r_{\mathrm{SC}}, r_{\mathrm{SK}}, r_{\mathrm{Sm}}, r_{\mathrm{Cm}}, r_{\mathrm{F}}\right.$ and $\left.r_{\mathrm{CP}}\right)$ depend on four specific rates $\left(q_{\mathrm{SC}, \max }, q_{\mathrm{SK}, \max }, q_{\mathrm{P}}\right.$ and $\left.q_{\mathrm{F}, \max }\right)$, three saturation constants $\left(k_{\mathrm{F}, \text { ext }}, k_{\mathrm{F}}\right.$ and $\left.k_{\mathrm{S}}\right)$, three yield coefficients $\left(Y_{\mathrm{SC}}, Y_{\mathrm{SK}}\right.$ and $\left.Y_{\mathrm{CP}}\right)$, one maintenance coefficient $\left(m_{\mathrm{S}}\right)$ and one conversion factor $\left(k_{\mathrm{m}}\right)$. With this set of parameters it is possible to calculate the specific maximum growth rate, $\mu_{\max }$.

This model doesn't account for a storage carbohydrates pool formation, nor a free intracellular phosphate pool, but just the formation of a pool including phosphate and low weight phosphorylated compounds. It also enlarges upon the previously Van Gulik et al. model by accounting for a formation of a high energetic compounds pool.

This model was applied to the experimental results obtained with of C. cardunculus suspended cells grown in a Gamborg $B_{5}$ medium supplemented with $2 \%$ sucrose [2] and the comparison between the simulated and experimental results are presented in Fig. 3. From this figure it can be seen that the patterns of phenol accumulation, biomass production, consumption of sucrose and uptake of extracellular phosphate are well described by the model, although the sucrose concentration during the initial part of the growth phase is underestimated and the phenol formation after the depletion of sucrose is overestimated by the model.

The maximum specific growth rate $\mu_{\max }=0.095$ day $^{-1}$ was calculated by Eq. (22). Table 2 summarizes the kinetic model parameters, some of those were obtained by nonlinear regression using ROK [6] and some others were previously calculated [2].

The discrepancies observed between the model response curves and the measured data, reflect the simplicity of this model as applied to a variety of more 
Table 2. Growth model kinetic parameters of Cynara cardunculus suspended cells

\begin{tabular}{lll}
\hline Maximum specific rate & Saturation constant & Yield and maintenance coefficient \\
\hline$q_{\mathrm{SC}, \max }=1.66 \times 10^{-1} \mathrm{mg} \cdot \mathrm{mg}^{-1} \cdot \mathrm{day}^{-1}$ & $k_{\mathrm{F}, \mathrm{ext}}=2.67 \times 10^{-1} \mathrm{mg} \cdot \mathrm{ml}^{-1}$ & $Y_{\mathrm{SX}}=0.580 \mathrm{mg} \cdot \mathrm{mg}{ }^{-1 *}$ \\
$q_{\mathrm{SK}, \max }=7.41 \mathrm{mg} \cdot \mathrm{mg}^{-1} \cdot \mathrm{day}^{-1}$ & $k_{\mathrm{F}}=2.67 \times 10^{-3} \mathrm{mg} \cdot \mathrm{mg}^{-1}$ & $Y_{\mathrm{SC}}=0.574 \mathrm{mg} \cdot \mathrm{mg}$ \\
$q_{\mathrm{F}, \max }=6.66 \times 10^{-2} \mathrm{mg} \cdot \mathrm{mg}^{-1} \cdot \mathrm{day}^{-1}$ & $k_{\mathrm{S}}=1.06 \times 10^{-2} \mathrm{mg} \cdot \mathrm{ml}^{-1}$ & $Y_{\mathrm{SK}}=0.0058 \mathrm{mg} \cdot \mathrm{mg}^{-1}$ \\
$q_{\mathrm{P}}=0.034 \mathrm{mg} \cdot \mathrm{g}^{-1} \cdot \mathrm{day}^{-1 *}$ & $k_{\mathrm{m}}=1.23 \times 10^{-3} \mathrm{mg} \cdot \mathrm{ml}^{-1}$ & $Y_{\mathrm{CP}}=1 \mathrm{mg} \cdot \mathrm{mg}{ }^{-1 *}$ \\
& & $m_{\mathrm{S}}=0.0066 \mathrm{mg} \cdot \mathrm{mg}^{-1} \cdot \mathrm{h}^{-1 *}$ \\
\hline
\end{tabular}

* Previously calculated [2]

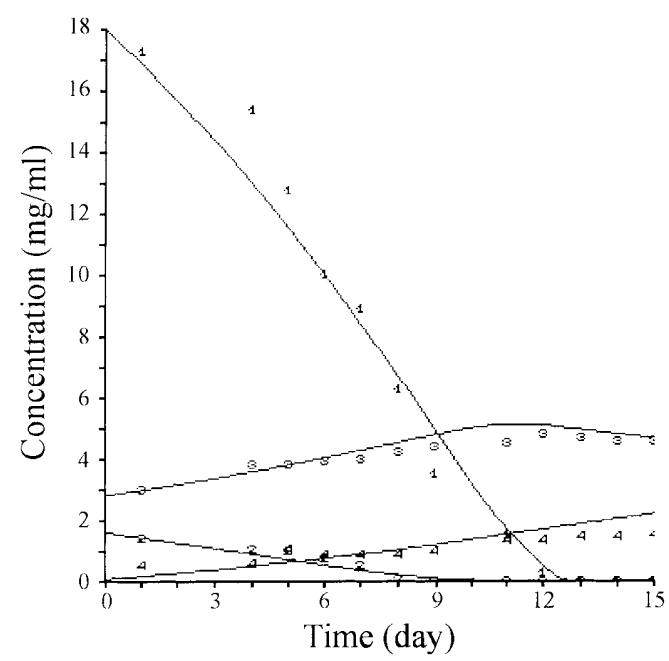

Fig. 3. Experimental data fitting of Cynara cardunculus suspended cells growth to a structured model: 1 Sucrose uptake from the extracellular medium; 2 Phosphate uptake from extracellular medium; 3 Biomass production; 4 Phenol formation and transport to the extracellular medium

complex responses in Cynara cardunculus tissue cultivation. However this model is very well capable of describing sucrose and extracellular phosphate uptake and conversions, structural biomass consumption and production, and secondary metabolites formation.

\section{References}

1. Lima Costa, M.E.: Cultura de Células Vegetais em Fermentador - Optimização do Crescimento da Cultura de Células em Suspensão de Cynara cardunculus L. M.Sc. thesis, University of Lisbon, Lisbon 1988

2. Lima Costa, M.E.: Cinética do Crescimento de Células em Suspensão de Cynara cardunculus em Reactores Biológicos. Ph.D. thesis, UCTA - University of Algarve, Faro 1994

3. Beeftink, H.H.; Van der Heijden, R.T.J.M.; Heijnen, J.J.: Maintenance requirements: Energy supply from simultaneous respiration and substrate consumption. FEMS Microbiol. Ecology 73 (1990) 203-210

4. Van Gulik, W.M.; Ten Hoopen, H.J.G.; Heijen, J.J.: A structured model describing carbon and phosphate limited growth of Catharanthus roseus plant cell suspensions in batch and chemostat culture. Biotechnol. Bioeng. 41 (1993) 771-780

5. Pires Cabral, P.C.: Modelação do Cresimento e da Produção de Metabolitos de Células em Suspensão de Cynara cardunculus L. M.Sc. thesis, Technical University of Lisbon, Lisbon 1995

6. Lobo, L.S.; Lobo, M.S.: Robust and efficient nonlinear regression of kinetics systems, using a direct search methods. Computers Chem. Eng. 15 (1991) 141-144 